\title{
SAFETY EVALUATION OF THYME ESSENTIAL OIL FEEDING ON LIVER AND KIDNEYS FUNCTION OF NORMAL HEALTHY RATS \\ Abdel-Moein, Nadia M. ${ }^{1}$ and Fatmma A. El-Hamid ${ }^{2}$ \\ 1- Department of Biochemistry, Faculty of Agriculture, Cairo University, Giza, Egypt. \\ 2- Department of Zoology, Faculty of Girls, Scientific Department, Buryda, Al-Qasseim, Saudi Arabia Kingdom.
}

\begin{abstract}
The present study deals with the safety evaluation of thyme essential oil used as a spice in foods on liver and kidney functions of rats. Therefore, the activities of some enzymes of rat plasma, i.e., alanine aminotransferase (ALT), aspartate aminotransferase (AST), and alkaline phosphatase (ALP) as well as rat plasma contents, i.e., total triglycerides, total cholesterol, LDL- cholesterol, HDL- cholesterol, urea, uric acid and creatinine were determined for rats administered with thyme essential oil at two concentrations of 200 and $400 \mathrm{ppm}$. In addition, histopathological examinations were performed in order to emphasis the results of biochemical determinations of liver and kidney functions. In general, the thyme essential oil induced little changes in aminotransferases activity in rat plasma and desirable changes in total cholesterol, LDL- cholesterol and HDL- cholesterol. On the contrary, this oil did not induce any changes in urea, uric acid and creatinine contents. Histological examination showed no changes in kidneys and liver tissues, except hydropic degeneration of some hepatocytes. So, the essential oil induced limited alteration in some parameters relevant to liver and kidneys functions. The outcome from these results that the essential oil of aerial part of thyme plant had harmless effect on liver and kidneys tissues.
\end{abstract}

Keywords: Thyme plant, Thyme essential oil, Enzyme activity, Liver function, Kidneys function, Plasma constitutes and Histopathological examinations.

\section{INTRODUCTION}

Numerous physiological and biochemical processes in the body may produce oxygen-centered free radicals and other reactive oxygen species as byproducts. Overproduction of such free radicals can cause oxidative damage to biomolecules, eventually leading to many chronic diseases in humans (Niki, 1997 and Poulson et al., 1998).

Medicinal plants have received growing attention in recent years as potential chemopreventive agents. The genus Thymus (lamiaceae) consists of over 300 evergreen species of herbaceous perennials and subshrubs, native to Southern Europe and Asia. Common thyme has a very long history of folk use for a wide range of ailments. It is very rich in essential oils and these are the active ingredients responsible for most of the medicinal properties (Duke and Ayensu, 1985). In particular, thyme is valued for its antiseptic and antioxidant properties, it is an excellent tonic and is used in treating respiratory disease and a variety of other ailments. The plant can be 
used fresh at any time of the year, or it can be harvested as it comes into flower and either be distilled for the oil or dried for treatments of tonsillitis, gum diseases, rheumatism, arthritis and fungal infections (Bown, 1995).

Thyme (Thymus vulgaris L.) has been used for its potential medicinal properties including antioxidant (Dorman et al., 2000; Cai et al., 2004; Lee et al., 2005), hepatoprotective and anticarcinogenic effects (Cai et al., 2004 and Sacchetti et al., 2005). This plant may contain a wide variety of free radical scavenging molecules, such as phenolic compounds, nitrogen compounds, vitamins, terpenoids and some other endogenous metabolites which are rich in antioxidant activity (Shahidi and Naczk, 1995; Cotelle et al., 1996; Velioglu et al., 1998; Zheng and Wang, 2001 and Cai et al., 2003). These antioxidant compounds possess anti-inflammatory, antiatherosclerotic, antitumor, antimutagenic, anticarcinogenic, antibacterial or antiviral activities to a greater or lesser extent (Owen et al., 2000 and Sala et al., 2002).

The aerial part of thyme plant or thyme essential oil is widely used in food as spices and in pharmaceutical industries where it possesses a powerful antioxidant and antitumor phenomenon. It seems that the safety limits of thyme essential oil are not known. Consequently, nutritional experiment was conducted to study its safety limits through evaluation of its effect on the liver and kidneys function. Therefore, the activities of alanine aminotransferase (ALT), aspartate aminotransferase (AST), and alkaline phosphatase (ALP) in plasma were measured, as well as the plasma levels of total cholesterol, LDL-cholesterol, HDL-cholesterol, total triglycerides, creatinine, urea and uric acidcontents. Histopathological examinations of liver and kidneys tissue of rats were conducted in order to emphasis the results of the biochemical determination for liver and kidneys function.

\section{MATERIALS AND METHODS}

\section{Source of materials}

Thymus vulgaris plant was obtained from Experimental Station of Medicinal plants, Faculty of Pharmacy, Cairo University, Giza.

\section{Chemicals and reagents}

All chemicals and reagents were obtained from Sigma Chemical Co. (London, Lab. Poole), England (Cairo branch); kits of all parameters were obtained from Biodiagonstic Co., 29 El-Tahreer Street, Dokki, Giza, Egypt.

\section{Extraction of essential oil from aerial part of thyme plant}

The essential oil of thyme plant, aerial part, was obtained by hydrodistillation according to Guenther (1961). The separated volatile oil was dried over anhydrous sodium sulfate before hold in glass bottle at $-20^{\circ} \mathrm{C}$.

\section{Animals:}

A number of 20 Wistr albino rats weights ranged between $80-100 \mathrm{~g}$ were obtained from Helwan Station for Experimental Animals, Helwan, Cairo, Egypt.

Nutritional experiment.

The basal diet consisted of corn starch $(65 \%)$, casein $(15 \%)$, corn oil $(10 \%)$, salt mixture $(4 \%)$, vitamin mixture $(1 \%)$ and cellulose $(5 \%)$ was 
prepared according to A.O.A.C. (2002). Experimental rats were fed on basal diet for two weeks and randomly divided into four groups (5 rats of each). The 1 st group was fed on the basal diet and served as normal control, while the rats of the 2 nd groups were injected subcutaneously with sunflower oil and considered as treated control. The rats of the $3 \mathrm{rd}$ and 4 th groups were injected subcutaneously with thyme essential oil which was dissolved in sunflower oil at does of 200 and 400 ppm, respectively each for four weeks.

At the end of the experiment (4 weeks), blood samples were taken from the orbital plexus and were placed in a dry clean centrifuge tube with anti-coagulant substance. The blood was centrifuged at $4731 \times \mathrm{g}$ for $10 \mathrm{~min}$. to separate the plasma which was kept frozen until analysis.

\section{Liver function tests}

The activities of plasma alanine aminotransferase (ALT, EC.2.6.1.2), plasma aspartate aminotransferase (AST, EC.2.6.1.1) were determined according to Reitman and Frankel (1957) and plasma alkaline phosphatase (ALP, EC. 3.1.3.1) were determined according to Kind and King (1954). The total triglycerides, total cholesterol, HDL- and LDL- cholesterol were determined according to the methods of Glick et al. (1986), Cohn et al. (1988), Harris et al. (1996) and Steinberg (1981), respectively.

\section{Kidney function tests.}

Plasma creatinine, urea and uric acid were determined according to Henry (1974), Patton and Crouch (1977) and Barham and Trinder (1972), respectively.

\section{Histopathological examination,}

At the end of the experiment, the rats were killed by decapitation and liver and kidneys organs were removed, stored in 10\% neutral formalin and embedded in paraffin wax. The organ was sectional the thickness of 5.6 microns and stained with haematoxylin and eoxin according to Culling (1965). Tissue sections were then examined using ordinary microscope for histological evaluation.

\section{Statistical analysis,}

The obtained data were subjected to analysis of variance and the least significant difference (L.S.D) test was calculated to allow comparison between the average values of the studied factors (Snedecor and Corchran, 1972).

\section{RESULTS AND DISCUSSION}

Thyme (Thymus vulgaris L.) is aromatic herb used extensively to add a distinctive aroma and flavor to food. Essential oils extracted from fresh leaves and flower can be used in aroma additives in food, pharmaceuticals and cosmetics. So, thyme has high nutritive and biological value and essential oil from thyme could be considered the most important. In the present study, one set of nutritional experiment was conducted to demonstrate the effect of thyme essential oil on liver and kidneys function and histopathological feature of liver and kidneys tissue of rats. 
Table (1) shows the effect of various concentrations of thyme essential oil (200 and 400 ppm) on ALT, AST and ALP activities. The activities of alanine aminotransferase (ALT), aspartate aminotransferase (AST) and alkaline phosphatase (ALP) were determined in rat plasma to evaluate the effect of thyme essential oil on liver function at two the levels (200 and $400 \mathrm{ppm}$ ).From the results in Table (1), it could be seen, the administration of the thyme essential oil of rats caused very slight significant stimulations in the activities of the aforementioned enzymes compared with normal control, except ALP enzyme upon treatment with essential oil at dose of $200 \mathrm{ppm}$. This stimulation induced in ALT activity by essential oil (200 and $400 \mathrm{ppm}$ ) compared with treated control and there are no significant differences between all treatments (Table1). Also, the results in Table (1) indicated that the AST and ALP activities were significantly stimulated upon treatment with essential oil at a dose of $400 \mathrm{ppm}$ compared with positive control. It was observed that there are no significant differences between all treatments in their effect on the ALP activity compared with both treated and normal control at the end of the experiment. These results are in agreement with those obtained by Akdogan et al. (2004) who found an increase of ALT and AST in rats when received Mentha piperita.

Table (1): Effect of thyme essential oil on the ALT, AST and ALP activities of rats plasma.

\begin{tabular}{|l|c|c|c|}
\hline \multirow{2}{*}{\multicolumn{1}{|c|}{ Treatment }} & \multicolumn{3}{c|}{ Enzymes activity (IU*/L) } \\
\cline { 2 - 4 } & ALT & AST & ALP \\
\hline Normal control & $9.31^{\mathrm{c}} \pm 0.67$ & $9.86^{\mathrm{a}} \pm 0.50$ & $72.46^{\mathrm{a}} \pm 0.81$ \\
\hline Treated control & $10.02^{\mathrm{a}} \pm 0.60$ & $10.04^{\mathrm{a}} \pm 0.22$ & $72.84^{\mathrm{a}} \pm 0.48$ \\
\hline Essential oil (200 ppm) & $12.06^{\mathrm{b}} \pm 0.80$ & $10.18^{\mathrm{a}} \pm 0.22$ & $72.78^{\mathrm{a}} \pm 1.22$ \\
\hline Essential oil (400 ppm) & $12.16^{\mathrm{b}} \pm 0.48$ & $11.12^{\mathrm{b}} \pm 0.52$ & $73.30^{\mathrm{a}} \pm 1.59$ \\
\hline LSD values at 5\% & 2.2 & 1.2 & 4.18 \\
\hline
\end{tabular}

The data are expressed as mean values \pm standard error.

*IU: refers to enzyme activity as international units.

\section{Plasma rat constituents.}

Table (2) shows the effect of thyme essential oil on aforementioned concentrations (200 and $400 \mathrm{ppm}$ ) on rat plasma constituents (total glycerides, total cholesterol, LDL- and HDL- cholesterol). The results show that there were no significant increase in total triglycerides at the end of the experiment upon administration of essential oil (200 and $400 \mathrm{ppm}$ ) and there were no significant variation between all treatments at the end of the experiment compared with treated and normal control rats. These data are of no harmony with those of Bolukbasi et al. (2006) who found that thyme oil supplementation led to increase plasma triglycerides. This is may be due to the type difference.

On the other hand, data in Table (2) show that there was significant decrease in the levels of serum total cholesterol upon administration of thyme essential oil at the two doses compared with treated control. Furthermore, the 
results for the treated and normal control rat experiment indicated that there were significant decreases in LDL- cholesterol levels at the end of the experiment at both doses (200 and $400 \mathrm{ppm}$ ). Concerning thyme essential oil at $200 \mathrm{ppm}$ level, there was non-significant decrease in LDL-cholesterol compared with normal control. It was observed that the essential oil (400 $\mathrm{ppm}$ ) possessed the highest effect on LDL-cholesterol level. The outcome from this set of experiments is, thyme essential oil did not cause harmful changes in the levels of LDL-cholesterol.

There was an inverse relationship between the level of HDLcholesterol and coronary heart disease, the high level of HDL-cholesterol decrease the incidence of atherosclerosis. Consequently, any substances that can increase the HDL-cholesterol level are highly desirable. The results in Table (2) indicated that there were significant rise in the levels of HDLcholesterol at both treatments and the essential oil at $400 \mathrm{ppm}$ exhibited the highest effect.

Table (2): Effect of thyme essential oil on the levels of plasma triglycerides, total cholesterol, HDL and LDL- cholesterol of rats plasma.

\begin{tabular}{|l|c|c|c|c|}
\hline \multicolumn{1}{|c|}{ Treatment } & $\begin{array}{c}\text { Total } \\
\text { triglyceride }\end{array}$ & $\begin{array}{c}\text { Total } \\
\text { cholesterol }\end{array}$ & $\begin{array}{c}\text { HDL- } \\
\text { cholesterol }\end{array}$ & $\begin{array}{c}\text { LDL- } \\
\text { cholesterol }\end{array}$ \\
\hline Normal control & $91.87^{\mathrm{a}} \pm 2.27$ & $97.24^{\mathrm{a}} \pm 4.08$ & $51.73^{\mathrm{a}} \pm 0.71$ & $27.13^{\mathrm{a}} \pm 3.35$ \\
\hline Treated control & $90.77^{\mathrm{a}} \pm 4.84$ & $99.19^{\mathrm{a}} \pm 6.07$ & $51.93^{\mathrm{a}} \pm 1.67$ & $29.11^{\mathrm{a}} \pm 4.16$ \\
\hline Essential oil $(\mathbf{2 0 0} \mathbf{~ p p m )}$ & $91.43^{\mathrm{a}} \pm 8.00$ & $97.56^{\mathrm{a}} \pm 6.64$ & $53.24^{\mathrm{b}} \pm 1.16$ & $26.04^{\mathrm{a}} \pm 6.78$ \\
\hline Essential oil $\mathbf{( 4 0 0} \mathbf{~ p p m )}$ & $91.65^{\mathrm{a}} \pm 3.23$ & $95.45^{\mathrm{a}} \pm 3.16$ & $54.81^{\mathrm{b}} \pm 0.91$ & $22.31^{\mathrm{a}} \pm 2.54$ \\
\hline LSD values at $\mathbf{5 \%}$ & 17.64 & 14.24 & 4.47 & 12.36 \\
\hline
\end{tabular}

The data are expressed as mean values $(\mathrm{mg} / \mathrm{dl}$ plasma) \pm standard error.

Table (3) indicates the levels of plasma uric acid, urea and creatinine due to the administration of thyme essential oil (200 and $400 \mathrm{ppm}$ ). The results for the control rat experiments showed non significant changes in the levels of uric acid, urea and creatinine. The same finding was obtained with rats administered various doses of thyme essential oil compared with treated control set. These results show no agreement with Akdogan et al. (2003) who found that Mentha spicata led to an increase in plasma urea and creatinine. Thus, thyme essential oil improved kidneys function. The outcome of this series of experiments suggests that thyme essential oil at 200 and $400 \mathrm{ppm}$ exhibit some limited changes in kidney and liver functions but it was within normal range, thus it seems to be safe on human health.

Table (3): Effect of thyme essential oil on the levels of plasma uric acid, urea and creatinine of rats plasma.

\begin{tabular}{|l|c|c|c|}
\hline Treatment & Uric acid & Urea & Creatinine \\
\hline Normal control & $4.01 \pm 0.22$ & $40.81 \pm 0.83$ & $0.73 \pm 0.10$ \\
\hline Treated control & $4.10 \pm .022$ & $38.28 \pm 0.74$ & $0.65 \pm 0.03$ \\
\hline Essential oil (200 ppm) & $4.00 \pm 0.44$ & $38.20 \pm 2.61$ & $0.67 \pm 0.08$ \\
\hline Essential oil (400 ppm) & $3.87 \pm 0.12$ & $36.71 \pm 2.06$ & $0.63 \pm 0.06$ \\
\hline LSD values at 5\% & 0.81 & 9.22 & 0.21 \\
\hline
\end{tabular}

The data are expressed as mean values (mg/dl plasma) \pm standard error. 


\section{Histopathological examination,}

Histopathological examination of rat liver tissues from control rats (normal one) revealed normal histological structure of hepatic lobules from central vein and cords (Figure 1). On the other hand, liver tissues of rats administered sunflower oil (treated control) showed some normal hepatocytes and other hepatocytes with hydropic degeneration (Figure 2). Examination of liver tissues of rats given thyme essential oil (200 and 400 ppm) showed no changes except hydropic degeneration of some hepatocytes (Figure 3 and 4).

Examination of kidneys tissue from rats fed on normal diet (normal control) revealed normal histology of renal parenchyma (Figure 5). Also, kidneys tissue of rats administered sunflower oil (treated control) revealed no histopathological changes (Figure 6). However, examined sections from rats administered thyme essential oil (200 and $400 \mathrm{ppm})$ revealed no histopathological changes except vacuolations of epithelial lining some renal tubules (Figures 7 and 8 ).

These results suggest that thyme essential oil (200 and $400 \mathrm{ppm}$ ) had very little effect on liver and kidneys were not affected. These results agreed quite well with the results of biochemical determination relevant to liver and kidney tests and are in agreement with Abdel-Moein. (2004) who reported that white and red thyme essential oil exhibited slight changes in liver tissues and had little effect on kidneys tissue of rats.

\section{Conclusion}

These data show that the essential oil is of great value in improvement of liver and kidneys function. Thus, it 's safe to human health.

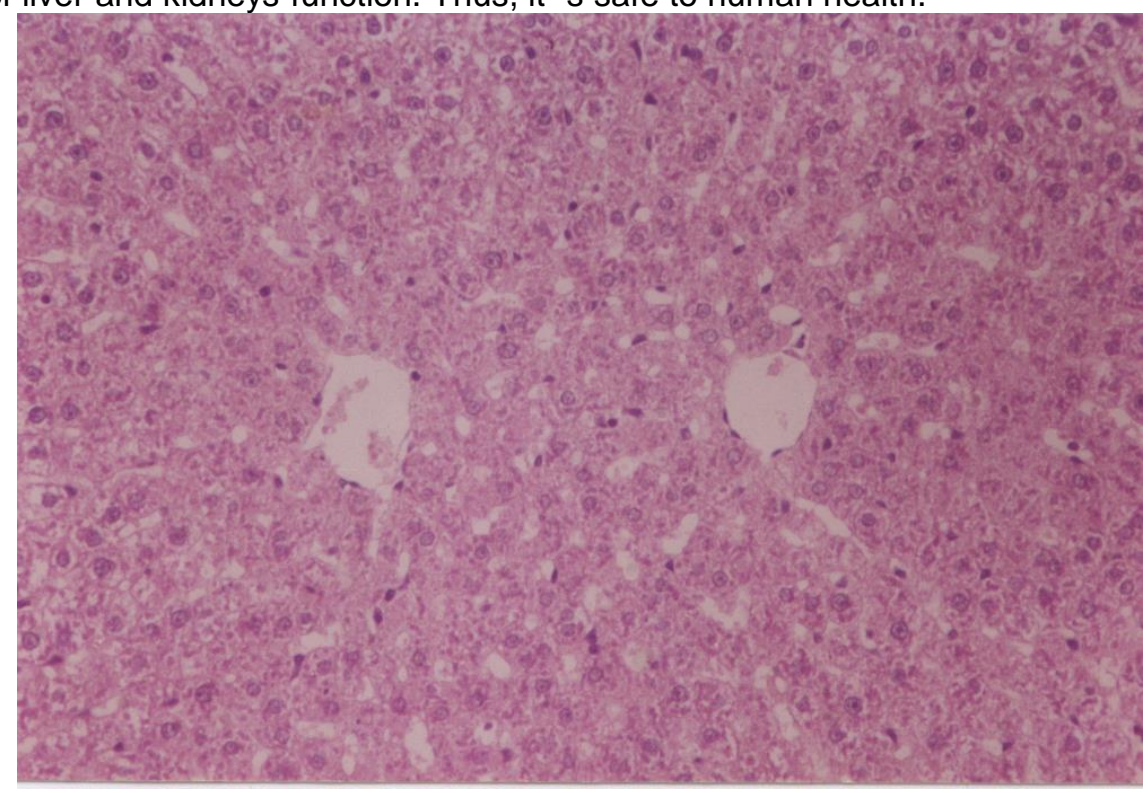

Figure (1): Liver tissues of control rats (untreated rats) showing the normal histology of hepatic lobule (Hand E X 200). 




Figure (2): Liver tissues of rats administered sunflower showing some normal patocytes (small arrow) and other hepatocytes with hydropic degeneration (Large arrow) (Hand E X 200).

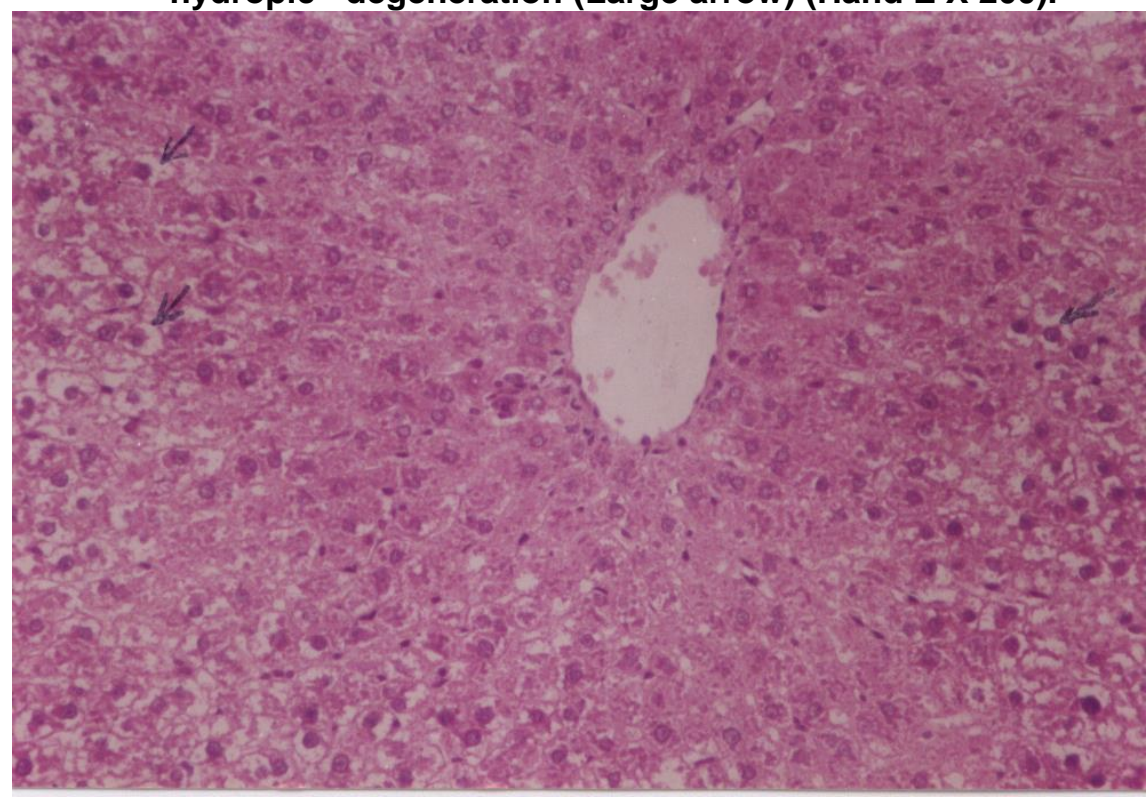

Figure (3): Liver tissues of rats given thyme essential oil (200 ppm) showing hydropic degeneration of some hepatocytes (Hand E X 200). 




Figure (4): Liver tissues of rats administered thyme essential oil (400 ppm) showing hydropic degeneration of some hepatocytes (Hand E X 200).

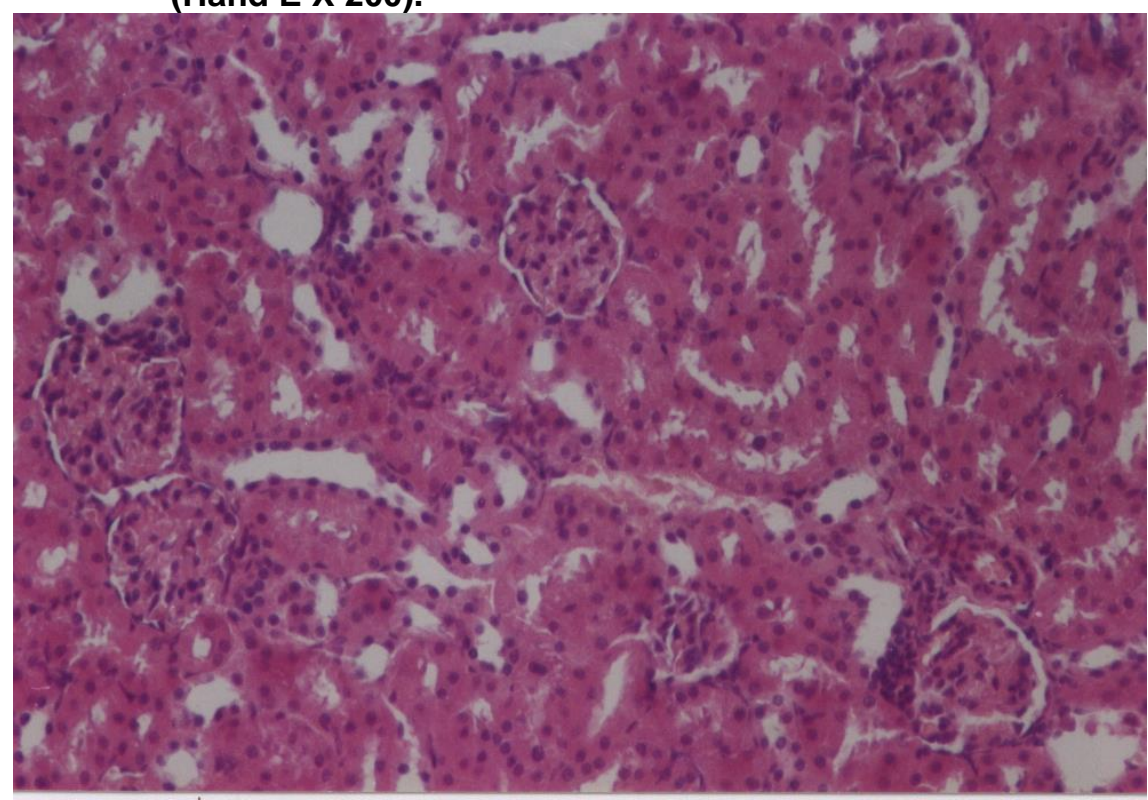

Figure (5): Kidney tissues of control rats (untreated rats) showing the normal histology of renal parenchyma (Hand E X 200). 


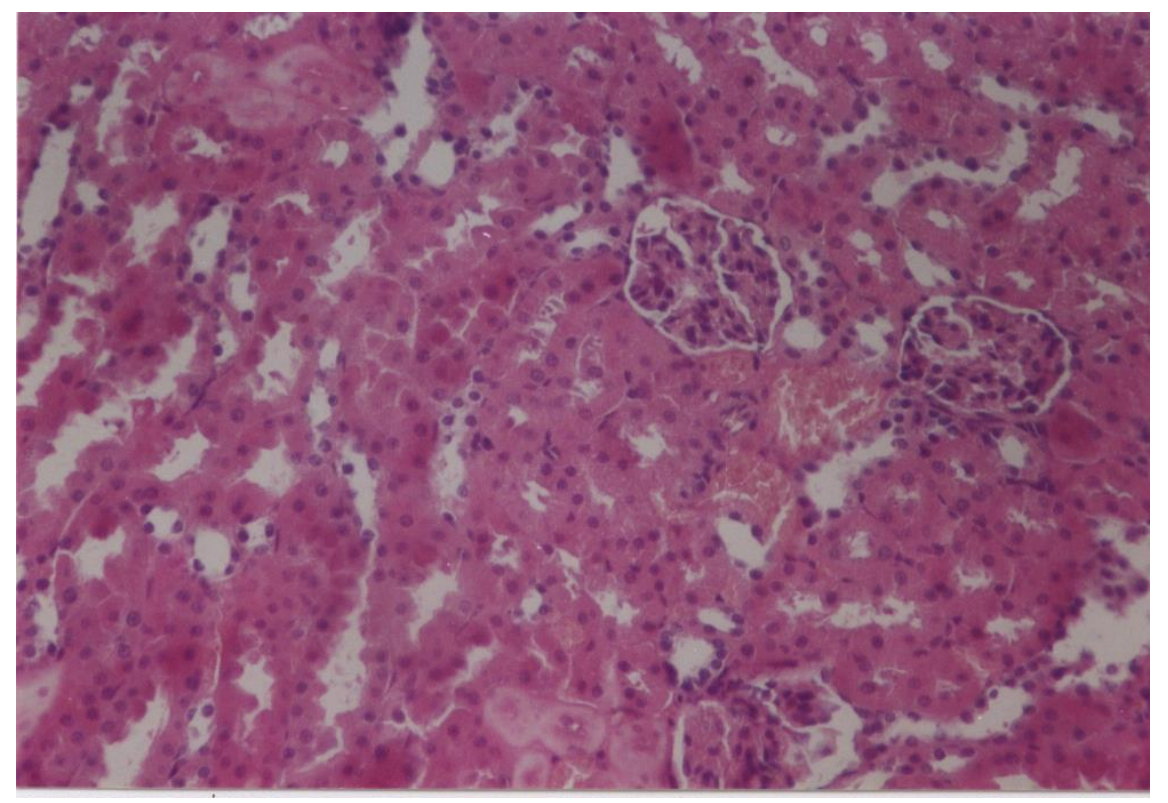

Figure (6): Kidney tissues of control rats administered sunflower showing no histopathogical changes (Hand E X 200).

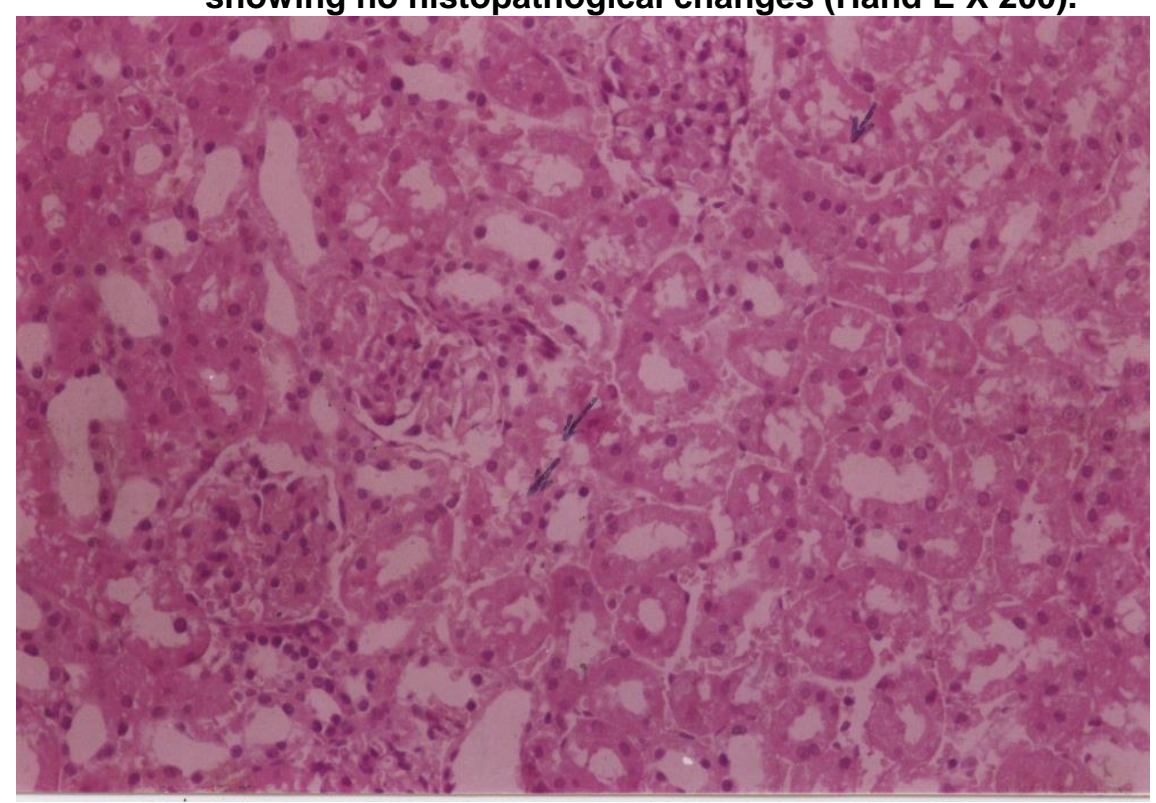

Figure (7): Kidney of rats administered thyme essential oil (200 ppm) showing vacuolations of epithelial lining some renal tubules (Hand E X 200). 




Figure (8): Kidney of rats administered thyme essential oil (400 ppm) showing vacuolations of epithelial lining some renal tubules (Hand E X 200).

\section{REFERENCES}

Abdel - Moein , Nadia , M. (2004). Safety evaluation of some synthetic and natural preservatives of cosmotic products. J. Agric. Sci. Mansoura Univ., $29: 5993$.

A.O.A.C. (2000). Official Methods of Analysis of the Association of Official Agriculture Chemists, $17^{\text {th }}$ ed., Published by USA.

Akdogan, M.; Kiline, I.; Oncu, M.; Karaoz, E. and Delibas, N. (2003). nvestigation of biochemical and histopathological effects of Mentha piperita L. and Mentha spicata L. on kidney tissue in rats. Human and Experi. Toxicol., 22: 213.

Akdogan, M.; Ozyuner, M.; Aydin, G. and Gokalp, O. (2004). Investigation of biochemical and histopathological effects of Mentha piperita labiatae and Mentha spicata labiatae on liver tissue in rats. Human and Experi. Toxicol., 23: 21.

Bölükbasi, S. C.; Erhan, M. K. and Özkan, A. (2006).Effect of dietary thyme oil and vitamin $E$ on growth, lipid oxidation, and meat fatty acid composition. J. Anal. Sci., 36: 189.

Barham, D. and Trinder, P. (1972). A colorimetric method for the determination of serum uric acid. Analyst., $97: 142$.

Bown, D. (1995). Encyclopedia of herbs and their uses. Dorling Kindersley, London. ISBN 0-7513-020-31. 
Cai, Y.Z: Luo, Q.; Sun, M. and Corke, H. (2003). Antioxidant activity of betalains from plants of the Amaranthaceae. J. of Agric. and Food Chem., 51: 2288.

Cai, Y. Z: Luo, Q.; Sun, M. and Corke, H. (2004). Antioxidant activity and phenolic compounds of 112 traditional Chinese medicinal plants associated with anticancer. Life Sci., 74: 2157.

Cohn, J. S.; McNamara, J. R. and Schaefer, E .J. (1988). Lipoprotein cholesterol concentration in the plasma of human subject as measured in the fed and fasted states. Clin. Chem., 34: 2456.

Cotelle, N., Bernier, J. L.; Catteau, J. P; Pommery, J.; Wallet, J. C. and Gaydou, E.m. (1996). Antioxidant properties of hydroxyflavones. Free Radical Bio. and Med., $20: 35$

Culling, C.F.A. (1965): Hand book of histopathological teqniques. $2^{\text {nd }}$ ed., Butterworth and Co. London.

Dorman, H.J.D.; Peter, S. and Stanley, G.D. (2000).In-vitro antioxidant activity of a number of plant essential oils and phytoconstituents. J. Essential Oil Res., 12: 241.

Duke, J.A. and Ayensu, E. S. (1985).Medicinal plants of China. Reference Publications, Inc. ISBN 0-917256-20-4.

Glick, M.R.; Ryder, K.W. and Jackson, S. A. (1986).Graphocal comparisons of interferences in clinical chemistry instrumentation. Clin, Chem., 32: 470.

Guenter, E. (1961).The "essential oils". vol. III, 4th Ed. D. Van Nostrand Company Inc., Princton, New Jersy, Toronto, New York, London.

Harris, N.; Galpchian, V. and Rifai, N. (1996). Three routine methods for measuring high density lipoprotein cholesterol compared with reference method. Clin. Chem., 42: 738.

Henry, R. J. (1974): Clinical chemistry, Principles and Technics. Second edition, Harper and Row, S. Aarons (Ed.), P 525.

Kind P.R.N. and King E.J. (1954). Estimation of plasma phosphatase by determination of hydrolysed phenol with amino-antipyrine. J. Clin. Pathol., 7: 322 .

Lee, S.; ano, k.; Shibamoto, T. and Lee, K. G. (2005).Identification of volatile components in basil (Ocimum basilicum $L$.) and thyme leaves (thymus vulgaris $L$.) and their antioxdant properties. Food chem., 91: 131.

Niki, E. (1997).Free radicals, antioxidants and cancer. In: Ohigashi, H., Osawa, T, Terao, J.; Watanabe, S. and Yoshikawa, T. (Eds.), Food Factors for Cancer Prevention. Springer, Tokyo, PP. 55.

Owen, R.W.;Giacosa, A.; Hull, W.E.; Haubner, R.; Spiegelhalder, B. and Bartsch, H. (2000). The antioxidant / anticancer potential of phenolic compounds isolated from olive oil. Europ. J. of Cancer, 36: 1235.

Patton, C.J. and Crouch, S.R. (1977).Spectrophtometric and Kinetics investigation of the bertholot reaction for determination of ammonia. Anal. Chem., 49: 464.

Poulson, H.E., prieme, H.E,; H.and Loft, S. (1998).Role of oxidative DNA damage in cancer initiation and promotion. Eur. J. of Cancer Prev., 7:9. 
Reitman, S. and Frankel, S. (1957).A colourimetric method for the determination of serum glutamic oxaloacetic and glutamic pyruvic transaminases. Am.J. Clin. Path., $28: 56$.

Sacchetti, G.; Maietti, S.; Muzzoli, M.; Scaglinanti, M; Manfredini, S.; Radice, M. and Bruni, R. (2005). Comparative evaluation of 11 essential oils of different origin as functional antioxidants, antiradicals and antimicrobials in food. Food Chem 91: 621.

Sala, A.; Recio, M.D., Giner, R.M.; Manez, S,; Tournier, H.Schinella, G.and Rios, J.L. (2002). Anti - inflammatory and antioxidant properties of Helichrysum italicum. J. of Pharmacy and Pharm., 45: 365 .

Shahidi, F. and Naczk, M (1995).Food phenolies: sources, chemistry, effects and applications Technomic pub. Co., Basel, Swizerland.

Snedecor, C. W. and Corchran, W. C. (1972). Statistical methods $7^{\text {th }}$ ed. lowa State Univeristy Press, Ames Lowa, USA.

Steinberg, D. (1981).Metabolism of lipoproteins at the cellular level in relation to atherogenesis. In lipoproteins. Atheroscl. and coron. Heart disease, $1: 31$.

Velioglu,Y.S.; Mazza, G.; Gao, L.and Oomah, B.D (1998). Antioxidant activity and total phenolics in selected fruits, vegetables and grain products. J. of Agric. and Food chem.., 46: 4113.

Zheng, W.and Wang, S.Y. (2001). Antioxidant activity and phenolics compounds in selected herbs . J. of Agric. and Food Chem., 49: 5165.

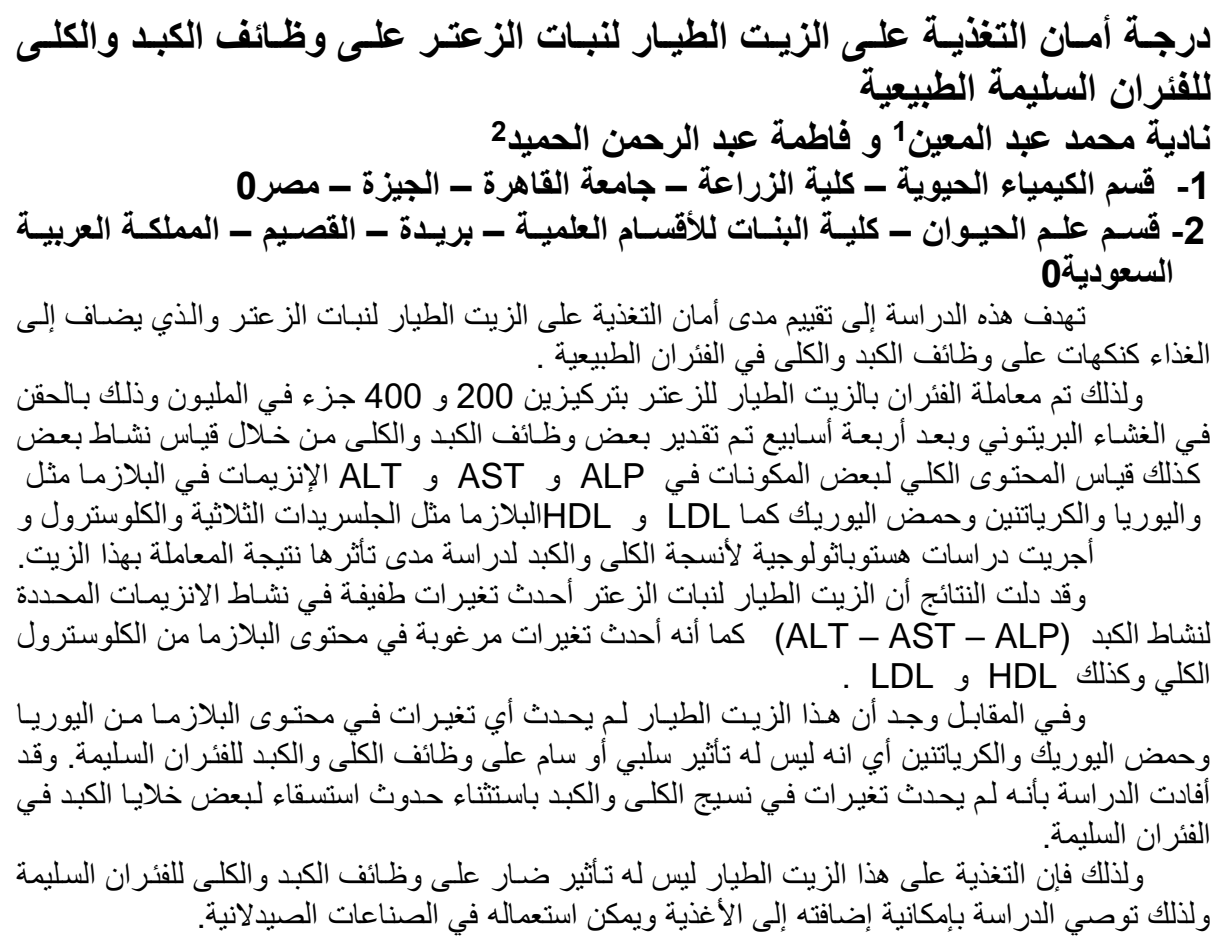

